\title{
Study on the Local Anti-Osteoporosis Effect of Polaprezinc-Loaded Antioxidant Electrospun Membrane
}

\author{
Xue Gao',* \\ Mohammed A Al-Baadani ${ }^{2, *}$ \\ Minjie Wu' \\ Ningyang Tong ${ }^{\prime}$ \\ Xinkun Shen ${ }^{2}$ \\ Xi Ding \\ Jinsong Liu ${ }^{2}$ \\ 'Department of Stomatology, The First \\ Affiliated Hospital of Wenzhou Medical \\ University, Wenzhou, 325016, People's \\ Republic of China; ${ }^{2}$ School and Hospital \\ of Stomatology, Wenzhou Medical \\ University, Wenzhou, 325000, People's \\ Republic of China \\ *These authors contributed equally to \\ this work
}

Background: Compared with the healthy condition, osteoporotic bone defects are often accompanied by poor osteogenesis and excessive reactive oxygen species (ROS), which pose serious challenges to bone augmentation and repair by normal resorbable guided bone regeneration (GBR) membrane.

Purpose: Polaprezinc (PZ) was loaded into polycaprolactone/gelatin (PG) hybrid electrospun nanofibers to fabricate a GBR membrane with antioxidant and osteogenesis ability.

Methods: A series of physicochemical characterization were performed by scanning electron microscopy, Fourier-transform infrared spectroscopy, and water contact angle measurement. In addition to membrane degradation and $\mathrm{PZ}$ release detection, membranes were tested for cell viability, differentiation, and protein expression in MC3T3-E1 cells by CCK8, alkaline phosphatase activity, mineralization, and Western blotting assays. The membrane osteogenic capacity in cranial bone defects was studied by micro-CT in vivo.

Results: PZ was successfully doped into the PCL/GEL nanofibers to form a hydrophilic GBR membrane. The cumulative release of PZ was closely related to the membrane degradation behavior. $\mathrm{PG} / 0.4 \% \mathrm{PZ}$ membranes produced the best protective effect on cell proliferation/differentiation under oxidative stress microenvironment; however, the PG/0.8\% PZ membrane was cytotoxic. Western blotting demonstrated that the PZ-loaded membrane upregulated the Nrf2/HO-1/SOD1 signaling molecules in a concentration-dependent manner. In addition, micro-CT results showed an abundant formation of new bones in the $\mathrm{PG} / 0.4 \% \mathrm{PZ}$ group compared to the PG group.

Conclusion: PZ-loaded degradable PG membranes (especially PG/0.4\%PZ) have great potential to accelerate bone regeneration in oxidative stress-related diseases.

Keywords: electrospun membrane, polaprezinc, antioxidant, osteogenesis, osteoporosis

\section{Introduction}

School and Hospital of Stomatology,

Wenzhou Medical University, 268\#

Xueyuan West Road, Lucheng District,

Wenzhou City, 325000, People's Republic

of China

Tel +86-577-880660l0

Email 20111902015@cqu.edu.cn

\section{Xi Ding}

Department of Stomatology, The First

Affiliated Hospital of Wenzhou Medical

University, Ouhai District, Wenzhou City,

325016, People's Republic of China

Tel +86-577-55579913

Email dingxi@wzhospital.cn
Despite inherent repair capabilities for small-size defects, extensive jaw bone defects from trauma, periodontal diseases, osteoporosis, and other possible reasons are significant clinical challenges for bone reconstruction. ${ }^{1}$ Guided bone regeneration (GBR) is a clinical method used for local jaw bone augmentation and defect repair. It utilizes a variety of barrier membranes (especially titanium mesh, polymer membrane, and degradable bio-collagen membrane) to block non-osteoblastic cell/tissue migration, stabilize bone substitute materials, and guide osteoprogenitors to the defect sites. ${ }^{2-4}$ Presently, there are various ways to fabricate biocompatible fiber membranes for tissue applications. Electrospinning is an uncomplicated/low-priced method for preparing 
membranes composed of continuous fibers at nanoscale and microscale, ${ }^{5}$ which also has been widely used for local drug loading and delivery systems. ${ }^{6}$ Electrospinning methods are becoming more diverse and versatile to achieve the purpose of sustained and controlled release of drugs, such as blend electrospinning, ${ }^{7}$ coaxial electrospinning, ${ }^{8}$ coelectrospinning, ${ }^{9}$ etc. Among these methods, blend electrospinning is the simplest and most cost-effective way based on traditional electrospinning, which allows membrane encapsulation of multiple drugs without affecting their biological activity. $^{10,11}$

Based on the sources, polymer barrier membranes can be classified into natural and synthetic membranes. The former, such as proteins [gelatin (Gel), collagen, etc.] and polysaccharides (chitosan, cellulose, etc.), offer superior biocompatibility, while the latter [such as polylactic acid (PLA) and polycaprolactone (PCL)] have better drug encapsulation ability. Among these materials, Gel is a natural, highly biodegradable, biocompatible, and accessible polymer; ${ }^{12}$ PCL is a synthetic, slowly bioresorbable and low-priced polymer. ${ }^{13}$ Both materials have been prepared into biodegradable electrospun nanofibrous membranes. However, the membranes prepared solely from natural or synthetic polymer have certain defects; therefore, many studies have attempted to evaluate the properties of Gel/PCL composite resorbable membranes. ${ }^{14}$ Although resorbable membranes are commonly used in clinical surgery mainly focusing on guiding bone regeneration in healthy bone, ${ }^{15}$ little attention has been paid to its applications in the osteoporotic bone. Previous studies showed that conventional absorbable collagen membrane or some other composite scaffolds applied to local GBR under osteoporotic conditions produced less bone formation with poor bone quality. ${ }^{16-19}$

Osteoporosis with low bone mass usually results in reduced bone strength and easy fracture. ${ }^{20}$ Notably, the mechanism of osteoporosis affecting alveolar bone healing is not yet clear. The jaw bone is susceptible to osteoporosis, showing the manifestation of thin and porous alveolar bone with poor bone repair. ${ }^{21}$ Meanwhile, other reports illustrate a correlation between osteoporosis and oxidative stress, which may express a higher level compared to a healthy condition. ${ }^{22,23}$ Oxidative stress is caused by overproduction of reactive oxygen species (ROS) and lack of adequate antioxidants. ${ }^{22}$ ROS are highly active molecules known for their dual roles as either detrimental or favorable to the biological system. ${ }^{24}$ The redox state microenvironment in cells changes during bone remodeling happens, inducing osteoclast resorption and osteoclastogenesis. ${ }^{22}$ Inhibition of overexpression of ROS can promote bone formation, ${ }^{25}$ such as using the biomaterials enhancing resistance to oxidative stress. ${ }^{26}$

Likewise, drugs with anti-oxidative stress ability such as polaprezinc (PZ) have attracted great attention. $\mathrm{PZ}$ is formed by chelation of zinc ( $\mathrm{Zn}$ ) with L-carnosine, which offers dual benefits of both ingredients. ${ }^{27,28} \mathrm{Zn}$ can play an important role in various biological behaviors, ${ }^{29,30}$ including normal cell proliferation/differentiation, ${ }^{31}$ oxidative stress, ${ }^{32}$ and osteogenesis/osteolysis, etc. ${ }^{33}$ Meanwhile, L-carnosine, composed of L-histidine and $\beta$-alanine, can chelate metal ions, ${ }^{34}$ and usually acts as buffer $^{35}$ or antioxidant $^{36}$ in the body. Furthermore, many studies investigated the benefits of $\mathrm{PZ}$ on gastric ulcers, ${ }^{37}$ oral mucositis, ${ }^{38}$ taste disorders, ${ }^{39}$ bulimia nervosa, ${ }^{40}$ pressure ulcers, ${ }^{41}$ and so on. The anti-oxidative/anti-inflammatory functions of PZ are the main mechanisms behind its biological effects. ${ }^{42}$ Interestingly, few studies reported or confirmed that PZ can be loaded into electrospinning membranes and play a corresponding role in a certain and special releasing way.

Taken together, an absorbable membrane with superior local anti-oxidative stress/anti-osteoporosis properties containing antioxidant drug is worth exploring. Herein, for the first time, we encapsulated PZ into the PCL/Gel hybrid nanofiber membranes through the blend electrospinning technique to obtain good local anti-osteoporosis and osteoinduction effects. Furthermore, a series of tests were performed to evaluate its osteogenic and antioxidant bioactivity under normal/oxidative stress conditions.

\section{Materials and Methods}

Fabrication and Characterization of Blend Drug-Loaded Nanofibers

PCL (Mn 80,000) and Gel were provided by Sigma (Aldrich-USA) and Aladdin (Shanghai, China), respectively. PZ was purchased from Shanghai Yuanye BioTechnology Co., Ltd (Shanghai, China). The PZ-loaded PCL/Gel hybrid fibers were fabricated as described previously, ${ }^{43}$ as shown in Figure 1A. Briefly, $10 \mathrm{w} / \mathrm{v} \%$ Gel [dissolved in 2,2,2-Trifluoroethanol (TFEA)] and 10 $\mathrm{w} / \mathrm{v} \%$ PCL (dissolved in TFEA) were mixed in equal volumes and stirred overnight to obtain a cloudy solution. Then, $20 \mu \mathrm{L}$ acetic acid and different doses of PZ $(0,0.2$, $0.4,0.6$, or $0.8 \%$ ) were added and continued to stir for another $6 \mathrm{~h}$. After that, the mixture was electrospun into 
A

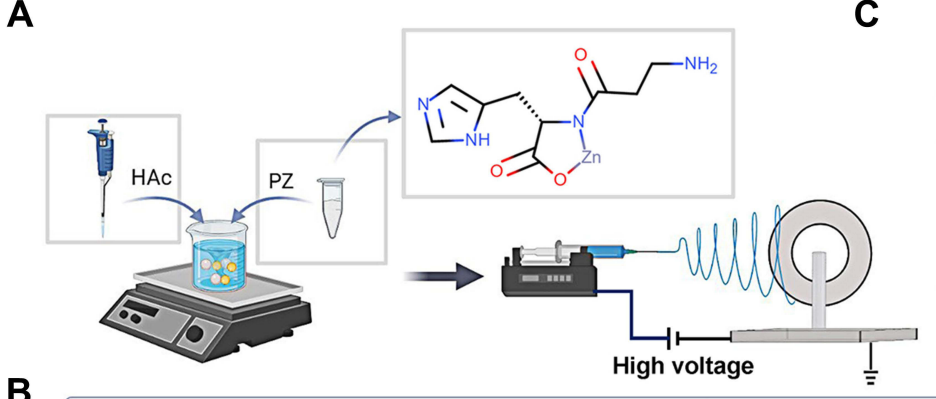

B
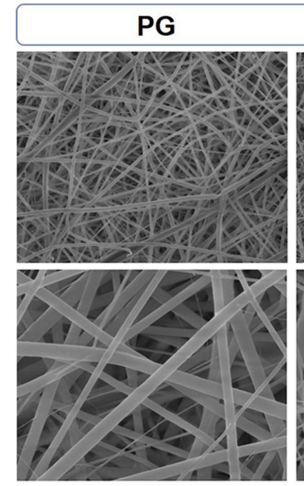

C

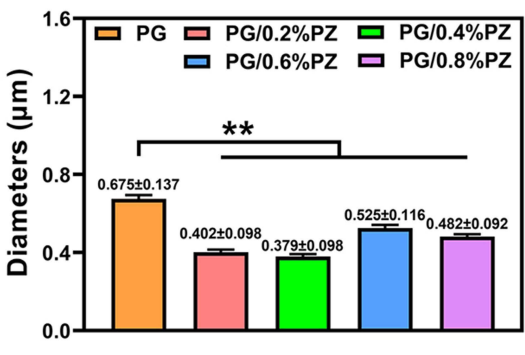

$\mathrm{PG} / 0.6 \% \mathrm{PZ}$

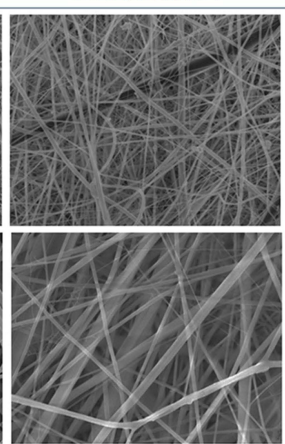

$\mathrm{PG} / 0.8 \% \mathrm{PZ}$

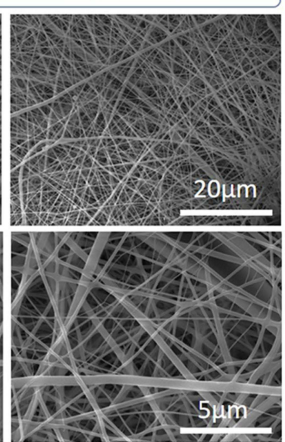

Figure I (A) Schematic illustration of the preparation of PCL/Gel blend membrane loaded polaprezinc; (B) scanning electron microscopy (SEM) images of various PZloaded nanofibers; $(\mathbf{C})$ the average diameters of different nanofibers. Error bars represent mean $\pm S D, * * p<0.0$ I.

nanofibers (named as PG, PG/0.2\%PZ, PG/0.4\%PZ, PG/ $0.6 \% \mathrm{PZ}, \mathrm{PG} / 0.8 \% \mathrm{PZ}$, respectively) as follows: voltage, 15 $\mathrm{KV}$; flow rate, $1.5 \mathrm{~mL} / \mathrm{h}$; rotational speed, $300 \mathrm{rpm}$; distance between needle and collector, $15 \mathrm{~cm}$. Then all collected membranes were dried and stored under vacuum for subsequent experiments.

Scanning electron microscopy (SEM, Zeiss AURIGAFlB, Germany) was applied to observe the morphology of different nanofibers. Using Image J software, 50 filaments at random locations were measured to determine the fiber diameter of each sample. Next, the chemical composition of different nanofibers was evaluated using Fourier-transform infrared spectroscopy (FTIR, Nicolet 8700, Thermo Electron Corporation, US). Furthermore, the surface wettability of different membranes was evaluated by estimating water contact angle (WCA) using a Contact Angle device (WCA, Model 200, Future Scientific, China). The images of water droplets $(3 \mu \mathrm{L})$ recorded at different time $(0,5,10 \mathrm{~s})$ were used for WCA analysis.

\section{Degradation Property of Nanofibers}

The degradation behaviors of $\mathrm{PG}$ and $\mathrm{PG} / 0.4 \% \mathrm{PZ}$ nanofibers were measured in vitro by immersing the samples (2 $\times 2 \mathrm{~cm}^{2}$ ) into $10 \mathrm{~mL}$ PBS at $37{ }^{\circ} \mathrm{C}$. Before soaking, the membranes were dried and weighed $\left(\mathrm{W}_{0}\right)$. At a pre-set time interval, the nanofibers were cleaned with deionized water to eliminate impurities. Then, the soaked samples were vacuum dried and weighed $\left(\mathrm{W}_{\mathrm{t}}\right)$. The mass loss was calculated as follows: Mass loss $(\%)=\left(\mathrm{W}_{0}-\mathrm{W}_{\mathrm{t}}\right) / \mathrm{W}_{0} \times$ $100 \%$. Moreover, the morphology of degraded nanofibers was observed by SEM.

\section{Release of PZ}

To determine the release behavior of $\mathrm{PZ}$ in the $\mathrm{PG} / 0.4 \% \mathrm{PZ}$ group, we quantified the released concentration of zinc ion $\left(\mathrm{Zn}^{2+}\right)$ in the soaking solution at different time. Briefly, the PG/0.4\%PZ was soaked in $10 \mathrm{~mL}$ PBS for $1,3,6,8,11$, 14 , and $21 \mathrm{~d}$ with constant shaking (100 rpm). At each preset time, the solution containing $\mathrm{Zn}^{2+}$ was collected entirely and substituted with new $10 \mathrm{~mL}$ PBS. The collected solution was stored in Eppendorf tubes (3 repeat tubes for each time point) at $-20{ }^{\circ} \mathrm{C}$ until tested by inductively coupled plasma mass spectroscopy (ICP-MS, Thermo Fisher, USA).

\section{Cell Experiments Cell Viability}

All samples were sterilized with UV irradiation, and covered with titanium rings to prevent floating. MC3T3-E1 cells, purchased from the Shanghai Institute of Cell Biology, were seeded on the membranes at a density of 
$1 \times 10^{4}$ cells $/ \mathrm{cm}^{2}$ and cultured in $\alpha$-MEM medium with or without $300 \mu \mathrm{M}$ hydrogen peroxide $\left(\mathrm{H}_{2} \mathrm{O}_{2}\right.$, Sigma Co.). After 4 and $7 \mathrm{~d}$, the medium was substituted with $300 \mu \mathrm{L}$ fresh media and $30 \mu \mathrm{L}$ CCK-8 (Beyotime Biotechnology Co., Ltd.). After incubation for another $2 \mathrm{~h}, 200 \mu \mathrm{L}$ of media was collected in 96-well plates and the samples' absorbance was detected at $450 \mathrm{~nm}$ via a spectrophotometric microplate reader (Bio-Rad 680, USA).

\section{Alkaline Phosphatase (ALP) Activity}

MC3T3-E1 cells were cultured on different samples with normal or $300 \mu \mathrm{M} \mathrm{H}_{2} \mathrm{O}_{2}$-supplemented medium. After culturing for $4 / 7 \mathrm{~d}$ and rinsing the adherent cells with PBS, the cells were lysed in 1\% Triton X-100 solution at $4{ }^{\circ} \mathrm{C}$ for $40 \mathrm{~min}$. The ALP activity and total protein content were measured using the commercially available Kits [ALP Staining and Bicinchoninic acid (BCA) protein kits (Beyotime Biotechnology Co., Ltd.)] following the manufacturer's instruction at the absorbance of $520 \mathrm{~nm}$ and $562 \mathrm{~nm}$, respectively.

\section{Mineralization}

After culturing with the normal or $300 \mu \mathrm{M} \mathrm{H}_{2} \mathrm{O}_{2}$-supplemented medium for $14 \mathrm{~d}$, the MC3T3-E1 cells were treated using $4 \%$ paraformaldehyde. Then, alizarin red $(1 \%$, Solarbio Biotech Co., Ltd.) solution was applied to stain the adherent cells at $37{ }^{\circ} \mathrm{C}$. The calcified nodules were observed and imaged under a stereomicroscope. The mineralization was quantified by dissolving the stained nodules in $10 \%$ cetylpyridinium chloride and determined at $540 \mathrm{~nm}$.

\section{Western Blotting}

MC3T3-E1 cells were cultured with $300 \mu \mathrm{M} \mathrm{H} \mathrm{H}_{2} \mathrm{O}_{2}$-supplemented medium for $4 \mathrm{~d}$. Next, the total proteins were collected by $1 \%$ sodium dodecyl sulfonate (SDS) solution. $20 \mu \mathrm{L}$ protein extract was loaded on $10 \%$ SDS-polyacrylamide gel electrophoresis (SDS-PAGE). After transferring to polyvinylidene fluoride (PVDF) membranes, they were incubated with anti-Nrf2 (110 kDa, Proteintech), anti- $\beta$ actin (42 kDa, Proteintech), anti-HO-1 (28-33 kDa, Proteintech), and anti-SOD1 (16-20kDa, Proteintech) antibodies, respectively. The target proteins were further labeled with the HRP-conjugated secondary antibodies and visualized with enhanced ECL Western Blot Kit (Thermo Co.). The protein bands' intensity was quantified using the Image $\mathrm{J}$ software and normalized with that of $\beta$ actin.

\section{Animal Experiment}

\section{Establishment of Osteoporosis and Skull Defect}

\section{Animal Model}

All animal experiments were approved by the Animal Ethics Committee of Wenzhou Medical University and implemented in strict accordance with the guidelines of the Institutional Animal Care and Use Committee of Wenzhou Medical University [SYXK (Zhe) 2020-0014]. Ten female Sprague-Dawley mice (3 months, 200-220 g) were used to establish the osteoporosis model through bilateral ovariectomy surgery (OVX). After three months, all osteoporotic mice were subjected to bilateral $6 \mathrm{~mm}$ bone defects on calvarium. In each animal, two different membranes ( $\mathrm{PG}$ and $\mathrm{PG} / 0.4 \% \mathrm{PZ}$ ) were placed at two different defect sites. Postoperatively, antibiotics (penicillin $\mathrm{G}, 8000 \mathrm{U} /$ mouse) were injected intramuscularly for three continuous days to prevent infection and contamination.

\section{Micro-Computed Tomography (Micro-CT) Detection}

To observe osteogenesis in skull defects and compare the healing difference between PG and PG/0.4\%PZ groups, all mice were sacrificed to harvest the calvarial specimens. All specimens were sorted and fixed in formalin after removing the excess soft tissue. A radiographic scan was performed using micro-CT (Skyscan1176, Bruker, Germany). The images were then reconstructed with NRecon software (Bruker microCT, Germany). Briefly, the Data Viewer software was used to perform threedimensional reconstruction of scanned images and intercept the cross-sections, and then the CTAn software was applied to reconstruct the cross-sections and analyze the bone volume/total volume (BV/TV), trabecular thickness (Tb. Th), trabecular number ( $\mathrm{Tb} . \mathrm{N})$, and trabecular separation (Tb. Sp). The typical cross-sections images were then adjusted and saved by CTvox and CTvol. The data of $\mathrm{Tb}$. Th, Tb. N, and Tb. Sp were normalized with that of $\mathrm{PG}$ as a reference.

\section{Statistical Analysis}

All individual experiments were repeated more than three times. Results were statistically analyzed using Student's $t$-test and analysis of variance (ANOVA) performed by OriginPro software (version 9.0) and GraphPad Prism (version 8.3), and expressed as mean \pm standard deviation (SD). $p<0.05$ and $p<0.01$ denoted statistical significance of the data, corresponding to 95 and $99 \%$ confidence intervals, respectively. 


\section{Results and Discussion}

\section{Characterization of Various Nanofibers}

The SEM images of different nanofibers were shown in

Figure 1B. All fibers presented a randomly oriented structure with a relatively uniform glossy shape and conformation. PZ incorporation significantly affected the morphology of the nanofibers. Some small and irregular granules were observed in the $\mathrm{PG} / 0.6 \% \mathrm{PZ}$ and $\mathrm{PG} / 0.8 \% \mathrm{PZ}$ groups, revealing that large doses of $\mathrm{PZ}$ were not dissolved completely. Furthermore, the average diameters of $\mathrm{PG}, \mathrm{PG} / 0.2 \% \mathrm{PZ}$, $\mathrm{PG} / 0.4 \% \mathrm{PZ}, \mathrm{PG} / 0.6 \% \mathrm{PZ}$, and $\mathrm{PG} / 0.8 \% \mathrm{PZ}$ nanofibers were $0.675 \pm 0.137,0.402 \pm 0.098,0.379 \pm 0.098,0.525 \pm 0.116$ and $0.482 \pm 0.092 \mu \mathrm{m}$, respectively (Figure 1C). Evidently, the addition of $\mathrm{PZ}$ caused the uneven structure of the fibers significantly decreasing their diameter $(p<0.01)$. The change in diameter was similar to that seen after loading other drugs into the PCL/GEL polymeric matrix. ${ }^{44}$

FTIR (Figure 2A) confirmed the chemical composition of scaffolds and indicated that PCL/Gel blend nanofibers were successfully fabricated. The peaks of Gel appeared at about $1650 \mathrm{~cm}^{-1}$ (amide I: the stretching vibration of $\mathrm{C}-\mathrm{O}$ bond) and $1542 \mathrm{~cm}^{-1}$ (amide II: the bending vibration of N-H bond). The typical peaks of PCL emerged at $1734 \mathrm{~cm}^{-1}$ (ester bond), $1168 / 1259 \mathrm{~cm}^{-1}$ (symmetric/asymmetric C-O-C stretching) and 2868/2950 $\mathrm{cm}^{-1}$ (symmetric/ asymmetric $\mathrm{CH}_{2}$ stretching). These bands of Gel and PCL were consistent with previous reports about $\mathrm{PCL} / \mathrm{Gel}$ hybrid electrospinning. ${ }^{45,46}$ Concerning PZ, a significant strong band emerged at $1259 \mathrm{~cm}^{-1}$ (amide III: the stretching vibration of $\mathrm{C}-\mathrm{N}$ bonds) and $1626 \mathrm{~cm}^{-1}$ indicating zinc-iron binding with L-carnosine. A previous study showed that metal coordination may affect the tautomeric equilibrium, causing a progressive increase in the tautomer II population and a decrease in the tautomer I population. ${ }^{47}$ Furthermore, we found that the peak at $1259 \mathrm{~cm}^{-1}$ disappeared after PZ loading into $\mathrm{PCL} / \mathrm{Gel}$ blend nanofibers, and two distinctive shifts were witnessed in vibration peaks at the nearby position. This might be due to similar vibration frequencies of PCL and PZ functional groups. When one vibration produces perturbation, a strong intermolecular interaction occurs between two molecules inducing a shift in one vibration to a higher frequency and the other to a lower frequency.

The surface wettability of biomaterials significantly impacts their cell adhesion and proliferation behaviors. PCL/Gel hybrid scaffolds were selected in this study for the excessive hydrophobic and hydrophilic nature of PCL and gelatin, respectively. ${ }^{12,44}$ All hybrid electrospun membranes showed favorable hydrophilicity with a water contact angle less than $90^{\circ}$ (Figure 2B). The addition of $\mathrm{PZ}$ increased the WCA at the 0th second, especially in the PG/ $0.4 \% \mathrm{PZ}$ and $\mathrm{PG} / 0.6 \% \mathrm{PZ}$ groups $(p<0.05)$. However, no significant differences were discovered at the 5th and 10th seconds. In summary, an increase in PZ concentration did not affect the surface wettability of membranes.
A

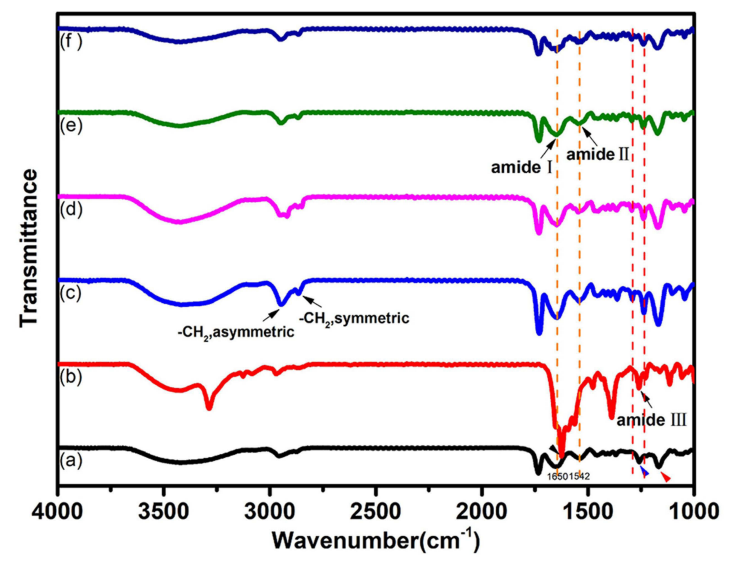

B

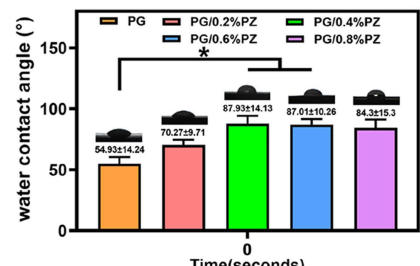

Time(seconds)

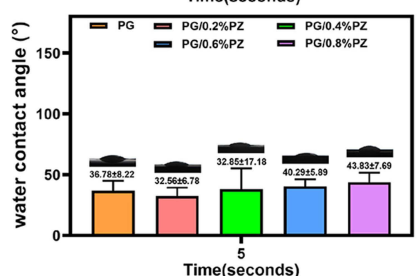

Time(seconds)

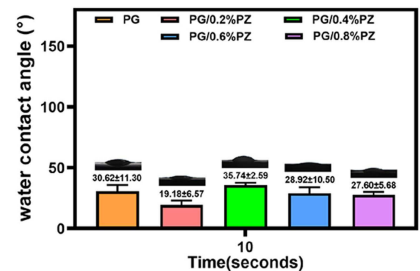

Figure 2 (A) The Fourier-transform infrared spectroscopy (FTIR) spectra of different nanofibers and pure PZ; (B) the water contact angle of different nanofibers obtained at 0,5 , and $10 \mathrm{~s}$, respectively. ${ }^{*} p<0.05$. 


\section{Degradation Behavior and PZ Release}

Concerning the degradation performance, $\mathrm{PCL} / \mathrm{Gel}$ blend nanofibers solved the shortcomings of slow degradation of PCL and rapid degradation of Gel. ${ }^{48}$ We measured the morphology and weight progressive changes of $P G$ and $\mathrm{PG} / 0.4 \% \mathrm{PZ}$ membranes after degradation at different time. The SEM images (Figure 3A) showed that all membranes changed from smooth to rough/porous, which was consistent with a previous study. ${ }^{43}$ Especially, the PG fibers appeared more pore-like structures and fractures than the PG/0.4\%PZ fibers; consequently, the mass loss for PG exceeded $50 \%$ on the 7 th day (Figure 3B). The mass loss of $\mathrm{PG} / 0.4 \% \mathrm{PZ}$ was observably higher than that of $\mathrm{PG}$ on day 1 and 4, however, the trend reversed for both membranes at 7, 14, and $21 \mathrm{~d}$ (Figure 3B). This can be explained as follows: the doping of $\mathrm{PZ}$ made the fiber thinner, which was easy to degrade and disappear in the early stage $;{ }^{49}$ the PG fiber also degraded in the early stage, but the resulting Gel molecules could have filled the pores. ${ }^{50}$ The further degradation of the membrane and the disappearance of Gel led to a higher mass loss in PG than that in the PZ-loaded group. In summary, PG/0.4\%PZ nanofibers could longer maintain the morphology, which is more conducive to the long-term release of $\mathrm{PZ}$.

We considered that the $\mathrm{Zn}^{2+}$ release corresponds to the release of PZ. Therefore, ICP-MS was performed to determine the cumulative release of $\mathrm{PZ}$. The cumulative release of $\mathrm{PZ}$ from $\mathrm{PG} / 0.4 \% \mathrm{PZ}$ samples increased following a certain trend (Figure 3C). Data shown in Figure 3B and $\mathrm{C}$ suggested that the $\mathrm{PG} / 0.4 \% \mathrm{PZ}$ membrane had a larger mass loss in the first $3 \mathrm{~d}$ causing a fast release of PZ $\left(18.67 \pm 0.69 \mu \mathrm{g} / \mathrm{cm}^{2}\right)$, reaching almost half of the total release in $21 \mathrm{~d}\left(38.02 \pm 1.33 \mu \mathrm{g} / \mathrm{cm}^{2}\right)$.

Based on the above results, we ensured that a simple hydrophilic GBR membrane loaded with PZ was successfully prepared, which could continuously release PZ. Also, the drug burst release occurred in the first $3 \mathrm{~d}$ and then slowed down. The initial rapid release may be due to the dissolution of surface aggregate in amorphous form causing the leaching of drugs encapsulated near the surface. ${ }^{7}$ This was deemed necessary to reduce the generation of ROS in the initial stage. The continuous release happened due to the longer drug diffusion path from the nanofibers center and the entanglement of PCL slowing down the gelatin degradation, ${ }^{51}$ which

A
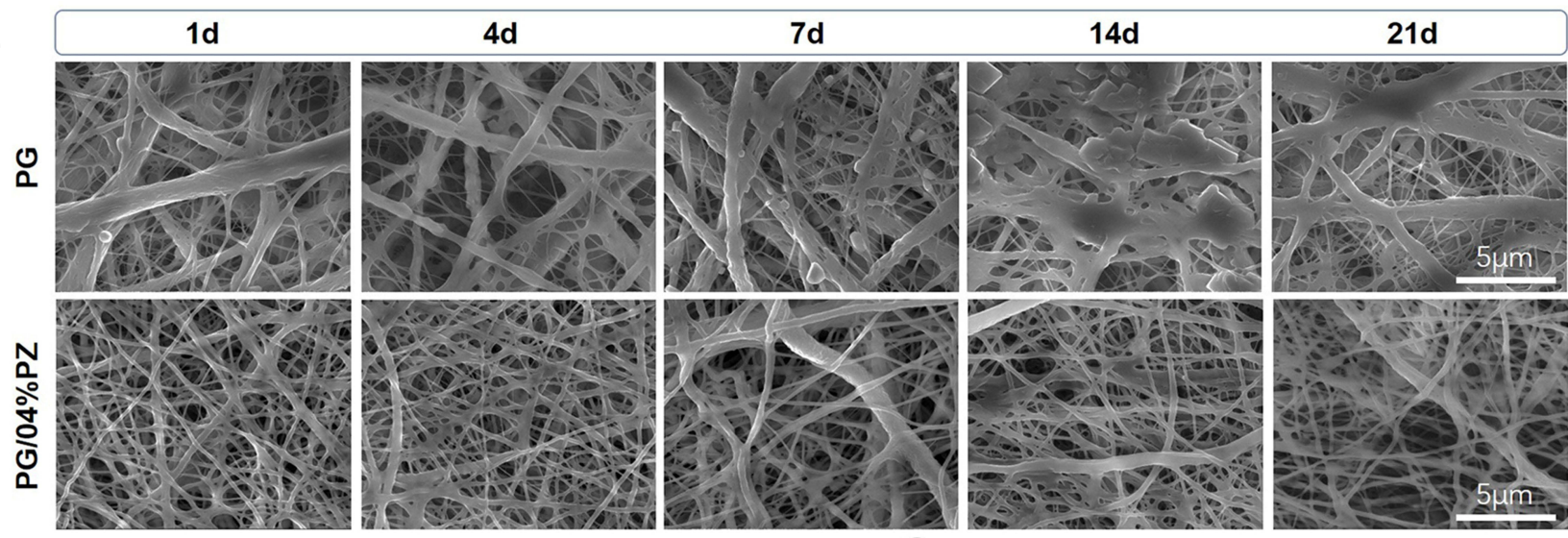

B

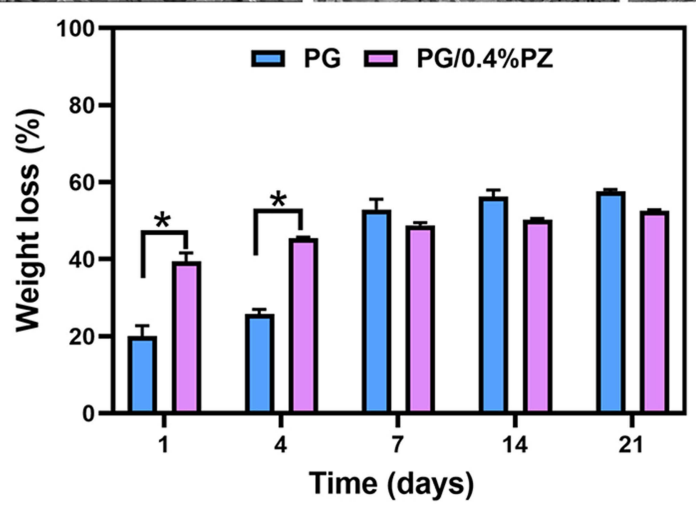

C

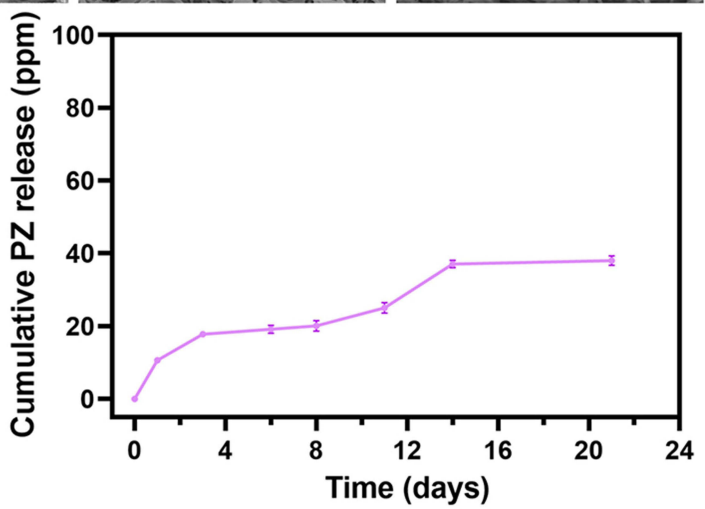

Figure 3 (A) Scanning electron microscopy (SEM) images of PG and PG/0.4\%PZ samples after immersion for I, 4, 7, I4, 2 I d; (B) the weight loss of PG and PG/0.4\%PZ after degradation for different time; $(\mathbf{C})$ the cumulative release of $\mathrm{PZ}$ from PG/0.4\%PZ specimens. Error bars represent mean \pm SD, $* p<0.05$. 
was also essential to maintain the antioxidant effect. In addition, a previous study had claimed that the different mixing ratios of Gel and PCL could lead to differences in fiber diameter and porosity, resulting in different drug release rates. $^{52}$ Therefore, to achieve desired drug release rate, the stability and support of structure must be tailored accordingly.

\section{Cell Viability}

The cell viability in $\mathrm{PG} / 0.8 \% \mathrm{PZ}$ group was significantly lower $(p<0.01)$ than that in other groups after incubation for 4 and $7 \mathrm{~d}$ under both normal and oxidative stress conditions (Figure 4). It indicated obvious cytotoxicity of PG/0.8\% PZ membrane which impacted the cell proliferation. The cell viability was significantly higher $(p<0.05)$ for $\mathrm{PG}, \mathrm{PG} / 0.2 \%$ $\mathrm{PZ}$, and $\mathrm{PG} / 0.4 \% \mathrm{PZ}$ than that of $\mathrm{PG} / 0.6 \% \mathrm{PZ}$ after $7 \mathrm{~d}$ under normal conditions. Moreover, the $\mathrm{PG} / 0.4 \% \mathrm{PZ}$ group showed the best cell viability after $7 \mathrm{~d}$ of $\mathrm{H}_{2} \mathrm{O}_{2}$ treatment. The absorbance values were $1.38 \pm 0.09$ (PG), $1.55 \pm 0.18$ (PG/ $0.2 \% \mathrm{PZ}), 1.96 \pm 0.10(\mathrm{PG} / 0.4 \% \mathrm{PZ}), 1.66 \pm 0.31(\mathrm{PG} / 0.6 \%$ $\mathrm{PZ})$, and $0.42 \pm 0.02(\mathrm{PG} / 0.8 \% \mathrm{PZ})$, respectively. The relatively low cell activity in the PG and PG/0.2\%PZ (low PZ loading) groups might be due to the MC3T3-E1 cells on the surface of these materials with weak antioxidant capacity could not withstand the accumulated oxidative stress within $7 \mathrm{~d}$. Earlier, PZ was shown to have dose-dependent protective effects on cells but produce cytotoxic effects at higher concentrations. ${ }^{53}$ Therefore, high-dose PZ released by PG/ $0.6 \% \mathrm{PZ}$ and $\mathrm{PG} / 0.8 \% \mathrm{PZ}$ (high PZ loading) exhibited some cytotoxicity reducing cell activity. Since the $\mathrm{PZ}$ release in the $\mathrm{PG} / 0.4 \% \mathrm{PZ}$ group was the most efficient to counter oxidative stress, this group showed the best cell viability at $7 \mathrm{~d}$.

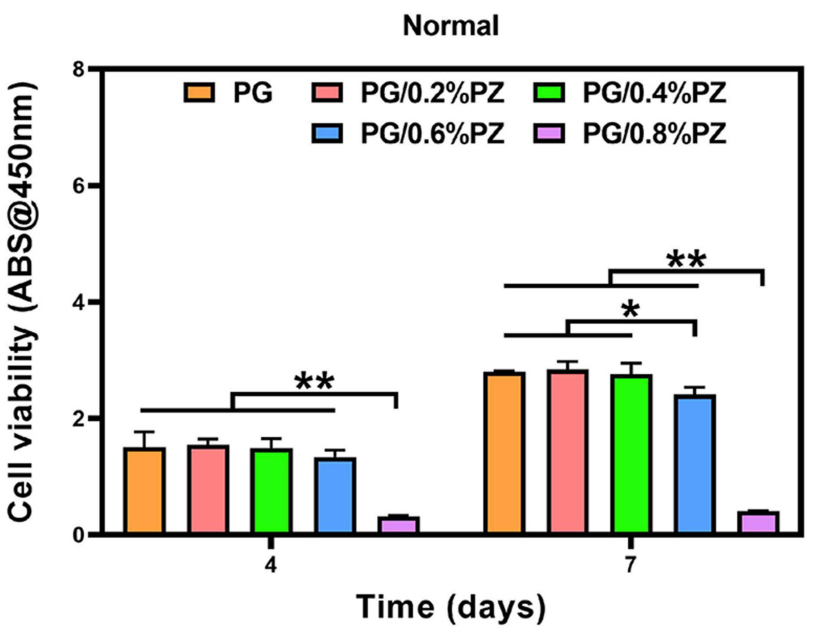

\section{Osteogenic Differentiation}

ALP staining and activity were measured to detect the early osteogenic differentiation after $7 \mathrm{~d}$ under normal and oxidative conditions. Under normal conditions, the ALP staining density was higher in the $\mathrm{PG} / 0.2 \% \mathrm{PZ}$ group than that in other groups, however, the staining density was the highest in the $\mathrm{PG} / 0.4 \% \mathrm{PZ}$ group after $\mathrm{H}_{2} \mathrm{O}_{2}$ treatment (Figure $5 \mathrm{~A}$ ). After $4 \mathrm{~d}$ of incubation under a normal microenvironment, the ALP activity of PG/0.2\%PZ and PG/0.4\%PZ were similar but higher $(p<0.01)$ than $\mathrm{PG}, \mathrm{PG} / 0.6 \% \mathrm{PZ}$, and $\mathrm{PG} / 0.8 \%$ PZ groups (Figure 5B). After $7 \mathrm{~d}$, the $\mathrm{PG} / 0.2 \% \mathrm{PZ}$ group showed the highest ALP activity $(p<0.01)$. Meanwhile, after incubation for $4 \mathrm{~d}$ under oxidative stress conditions, the PG/0.2\%PZ group showed a significantly different activity compared to the PG group (Figure 5C). After $7 \mathrm{~d}$, the ALP activity of the $\mathrm{PG} / 0.4 \% \mathrm{PZ}$ group was significantly higher than that of other groups, in line with the ALP staining results.

Next, the late osteogenic differentiation was further assessed by alizarin red staining. The $\mathrm{PG} / 0.4 \% \mathrm{PZ}$ group had more stained mineralized nodules than the other groups regardless of normal or $\mathrm{H}_{2} \mathrm{O}_{2}$-treated conditions (Figure 6A). The corresponding quantitative analysis results also confirmed this trend (Figure 6B and C). Meanwhile, the PG/ $0.8 \% \mathrm{PZ}$ group exhibited the lowest mineralization level after $14 \mathrm{~d}$, in line with the results of ALP activity. The mineralization of osteoblasts on various PCL/Gel nanofibers loaded with different doses of PZ (except for the PG/0.8\%PZ) also increased to different degrees. Therefore, membranes encapsulating PZ produced bone-promoting and antioxidative abilities, and the best drug loading concentration was $0.4 \%$.

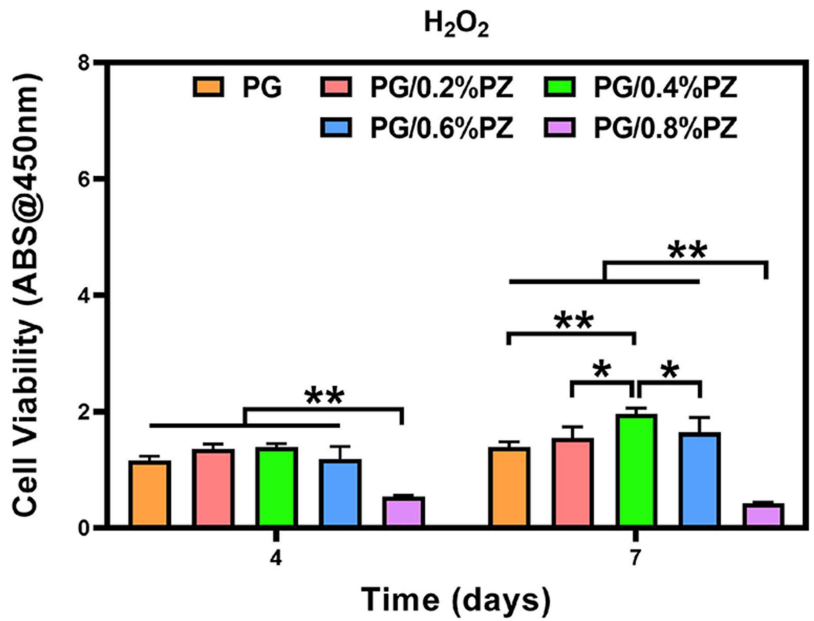

Figure 4 The cell viability of MC3T3-EI cells on different nanofibers after incubation for 4 and $7 \mathrm{~d}$ under normal and oxidative conditions. $* p<0.05$, ** $p<0.0 \mathrm{I}$. 


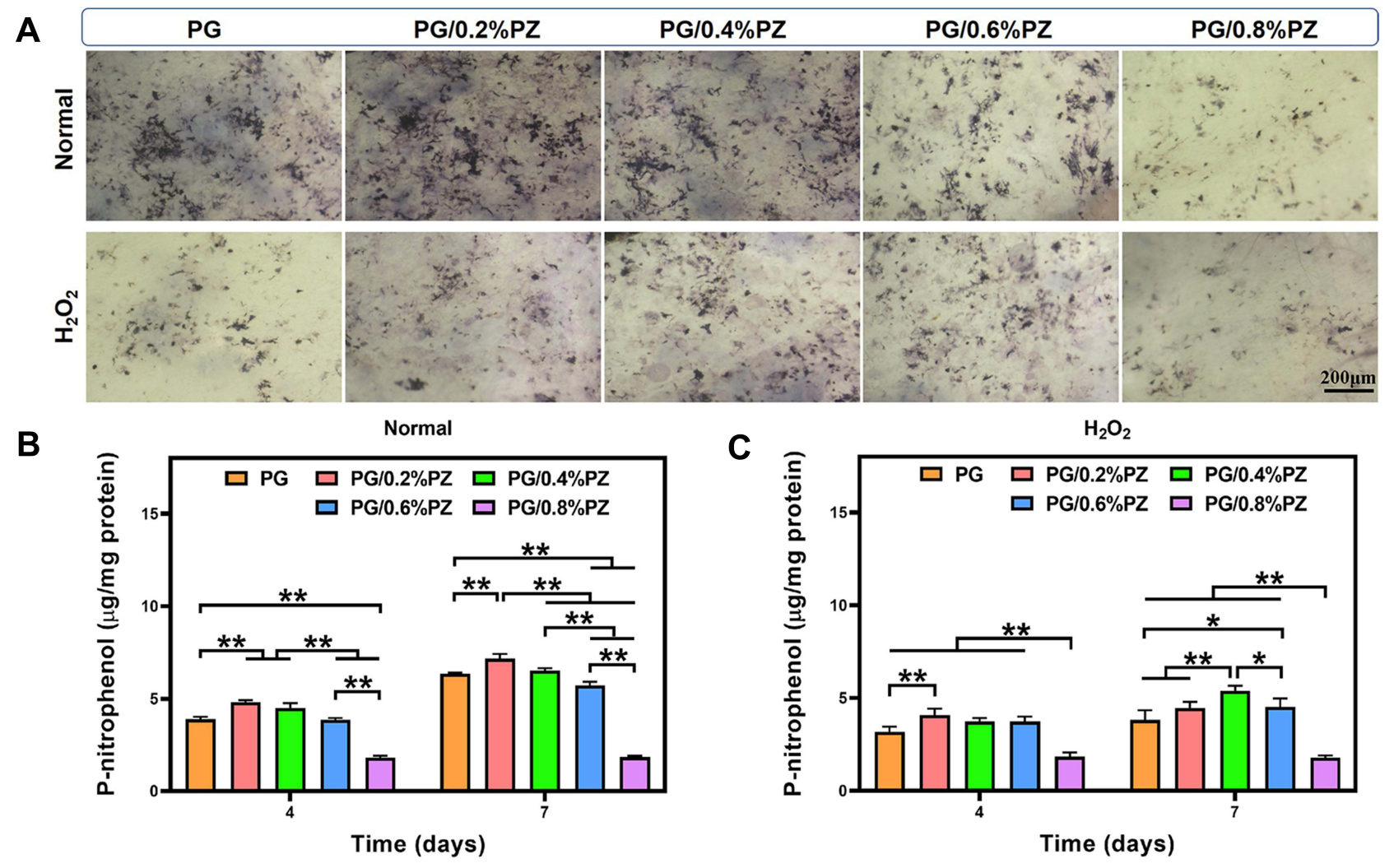

Figure 5 (A) Alkaline phosphatase (ALP) staining images of MC3T3-El cells after incubation for $7 \mathrm{~d}$; (B) quantitative analysis of ALP activity under normal conditions; and (C) quantitative analysis of ALP activity under oxidative conditions. Error bars represent mean $\pm \mathrm{SD}$, *p $<0.05$, $* * p<0.0$ I.

Based on the above cytological results, we concluded that PZ could effectively promote osteogenesis and restore the proliferation/differentiation of $\mathrm{H}_{2} \mathrm{O}_{2}$ damaged MC3T3E1 cells within a certain concentration range. In contrast, most previous studies focused on the antioxidant and antiinflammatory effects of $\mathrm{PZ},{ }^{54}$ with little reference to its bone-promoting properties. Nonetheless, whether the PZ releasing from the PG membrane has a direct effect on osteogenesis and its precise mechanism are worthy of our further exploration and verification.

\section{Signaling Pathway}

To further elucidate the role of $\mathrm{PZ}$ in antioxidant signaling pathway, we assessed the expression of Nrf2, HO-1, SOD1 proteins in MC3T3-E1 cells. The membrane with different concentrations of $\mathrm{PZ}$ increased the Nrf2/HO-1/ SOD1expression in a concentration-dependent manner compared with the PG group (Figure 7). Especially, the $\mathrm{Nrf} 2$ expression was observably upregulated $(p<0.05)$ in the $\mathrm{PG} / 0.4 \% \mathrm{PZ}$ and $\mathrm{PG} / 0.6 \% \mathrm{PZ}$ groups. No significant increment in the content of HO-1 or SOD1 was detected in PG with different PZ concentrations compared with the control group, however, they somewhat appeared to be on a higher side.

Notably, Nrf2 is a well-known regulator of cellular oxidation and can directly regulate the expression of HO1 and SOD. ${ }^{55}$ A previous study showed that PZ protected CCD-18co human normal colon fibroblast cells from oxidative stress by increasing metallothionein (MT) and SOD1 expression rather than activating Nrf2. ${ }^{56}$ Another study suggested that PZ could suppress inflammatory responses by activating the $\mathrm{Nrf}$ /HO-1 signaling pathway, mainly due to its $\mathrm{Zn}^{2+}$ component. ${ }^{57}$ In addition, $\mathrm{H}_{2} \mathrm{O}_{2}$ induced oxidative stress and inhibited osteoblastic differentiation. ${ }^{58,59}$ The relationship between the antioxidant system and osteogenesis had been studied in MC3T3E1 cells, ROS not only directly promote osteoclast formation, but also inhibit osteogenic differentiation by downregulating Runx2, ALP, osteocalcin, and other osteogenic markers. ${ }^{60}$ One previous research showed that Nrf2 affected osteogenesis by interfering with the function of Runx2 in the MC3T3-E1 cells, meanwhile, it regulated osteocalcin promoter activity via at least two pathways. ${ }^{61}$ Nrf2 and Runx2 are crucial transcription factor regulating 


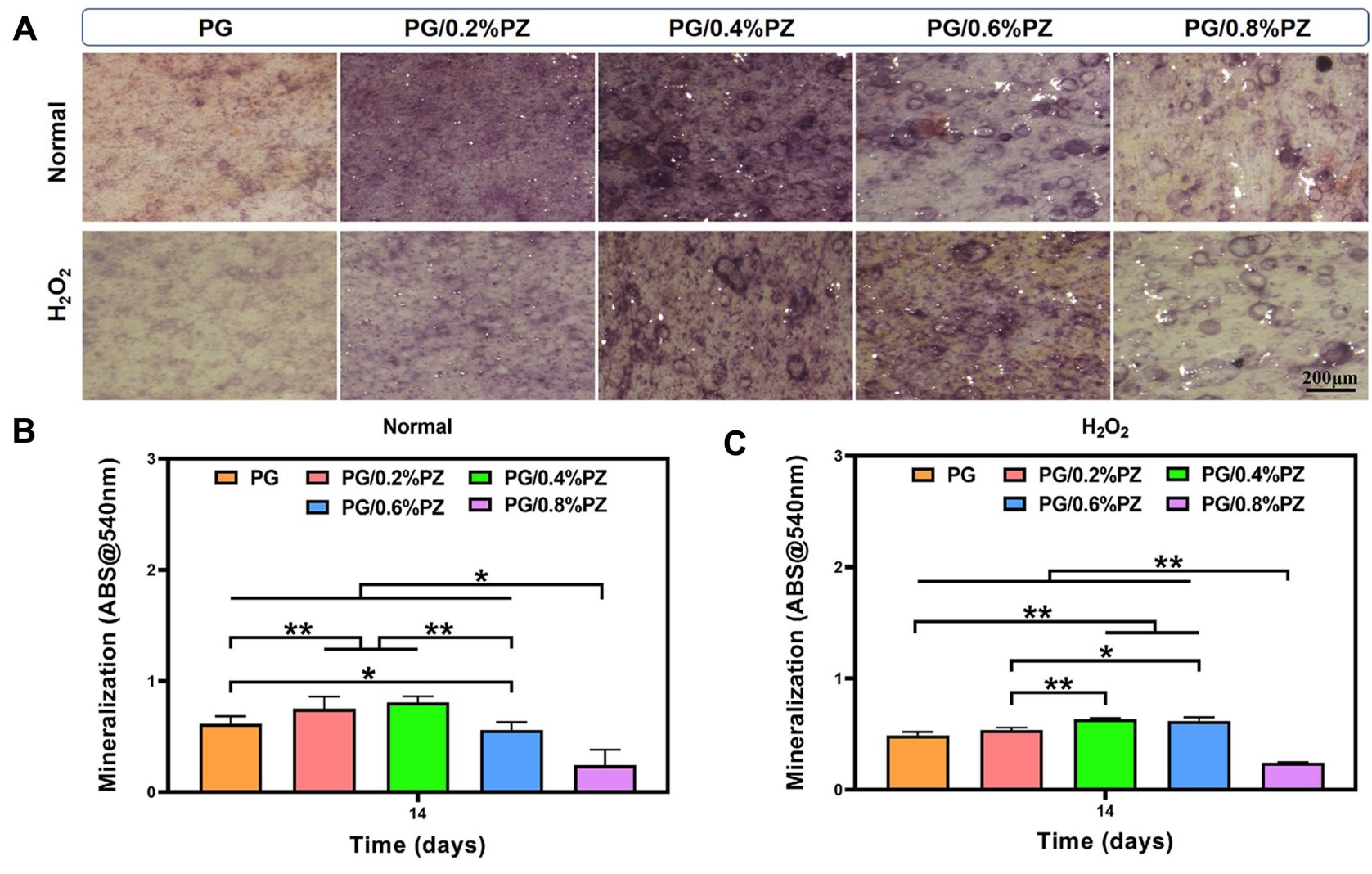

Figure 6 (A) Alizarin staining images of MC3T3-EI cells after incubation for $14 \mathrm{~d}$; (B) quantitative analysis of mineralization under normal conditions; and (C) quantitative analysis of mineralization under oxidative conditions. Error bars represent mean $\pm \mathrm{SD},{ }^{*} p<0.05, *^{*} p<0.0$.

antioxidative and osteogenic differentiation, respectively, which participate in multiple relative signaling pathways. Here, our study has only validated a part of the relevant signal pathway. Therefore, in the future, it is worthy to investigate the specific antioxidant signal pathways of $\mathrm{PZ}$ and the directly affected osteogenic signaling pathways.

\section{Osteogenesis in vivo}

To investigate the osteogenesis of target membranes in vivo, the $\mathrm{PG}$ and $\mathrm{PG} / 0.4 \% \mathrm{PZ}$ scaffolds were implanted into cranial bone defects of osteoporotic rats. Then cranial specimens were subjected to micro-CT analysis. The typical coronal and transverse images (Figure 8A) revealed that the $\mathrm{PG} / 0.4 \% \mathrm{PZ}$ group exhibited significant bone regeneration compared to the PG group. Also, the BV/TV and Tb. Th in $\mathrm{PG} / 0.4 \% \mathrm{PZ}$ group were observably higher than those in PG group $(p<0.05$ or $p<0.01)$ (Figure $8 \mathrm{~B}$ and $\mathrm{C}$ ). However, there were no significant differences between the two groups in Tb. $\mathrm{N}$ and $\mathrm{Tb}$. Sp (Figure 8D and E). Osteoporotic bone defects suffer from poor bone quality, such as loose cancellous bone, thinning of cortical bone, and thinning of trabecular bone. ${ }^{62}$ In addition, compared with normal bone tissue, osteoporotic bone tissue produces more ROS. ${ }^{20}$ In our studies, what we loaded into the blend electrospinning membrane is famous for its ability to antioxidative stress. We found that GBR membranes releasing PZ could effectively protect osteoblasts from ROS damage.

In summary, the aforementioned results collaboratively confirmed our hypothesis that the PZ-loaded electrospun membranes (especially $\mathrm{PG} / 0.4 \% \mathrm{PZ}$ ) had ability to resist oxidative stress and promote bone formation in the microenvironment of osteoporotic oxidative stress. We also partially proved that this function is closely related to the sustained-release PZ that effectively activates the antioxidant stress signaling pathways (NRF2/HO-1/SOD1). Nevertheless, more detailed molecular signal regulation mechanisms need to be elucidated in future studies.

\section{Conclusion}

We successfully encapsulated PZ into a GBR membrane that was fabricated by blend electrospinning of PCL and Gel. The addition of PZ resulted in a smaller diameter nanofiber membrane with good hydrophilicity. Under the oxidative stress microenvironment, $\mathrm{PZ}$ in a certain concentration 
A

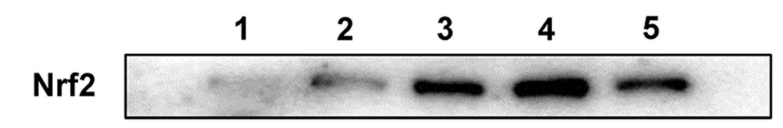

HO-1

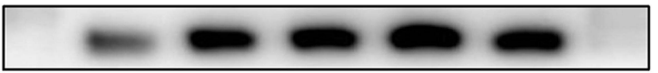

SOD1

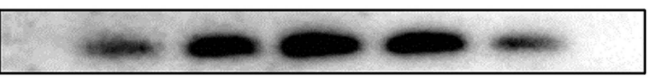

$\beta$-actin

C

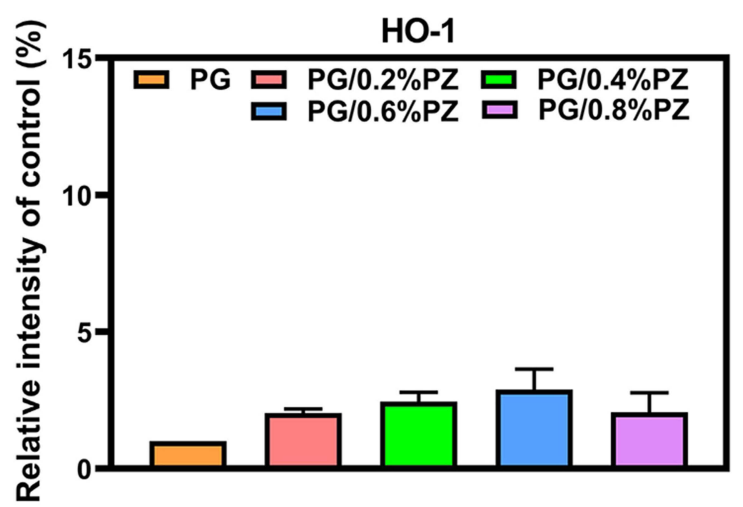

B

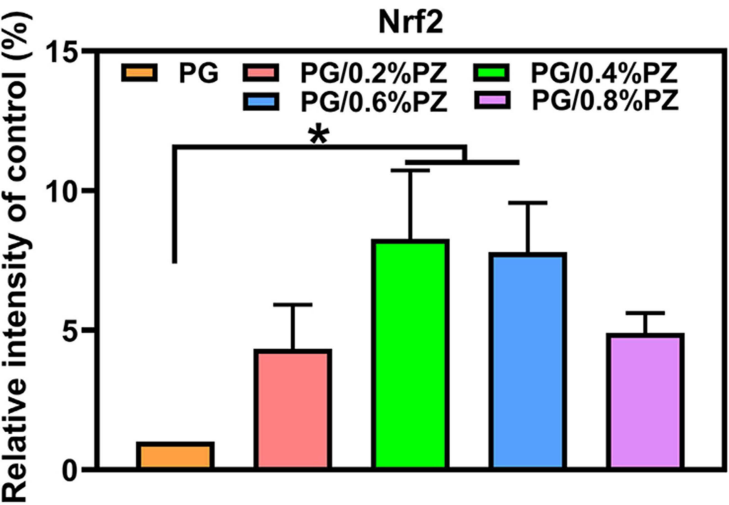

D

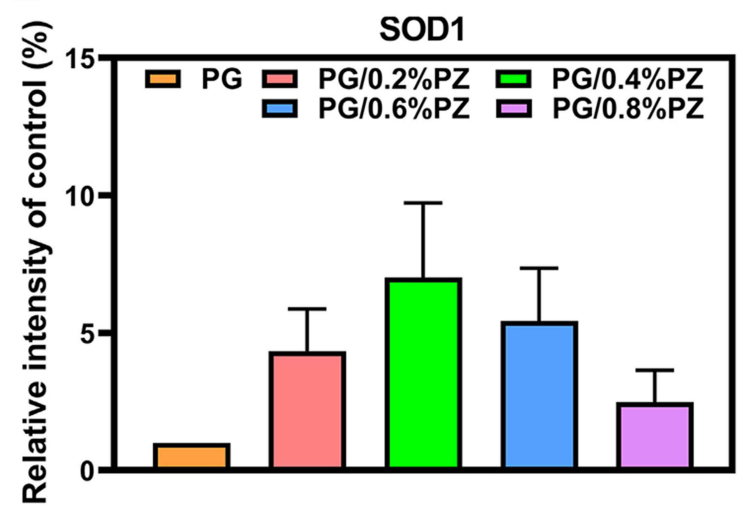

Figure 7 (A) Representative Western blotting images of HO-I/Nrf2/SOD In different groups (I - PG, 2 - PG/0.2\%PZ, 3 - PG/0.4\%PZ, 4 - PG/0.6\%PZ, 5 - PG/0.8\%PZ); quantitative statistics of $\mathrm{Nrf2} / \beta$-actin (B), HO-I/ $\beta$-actin (C), and SODI/ $\beta$-actin (D), respectively. Error bars represent mean \pm SD, ${ }^{*} p<0.05$.

A

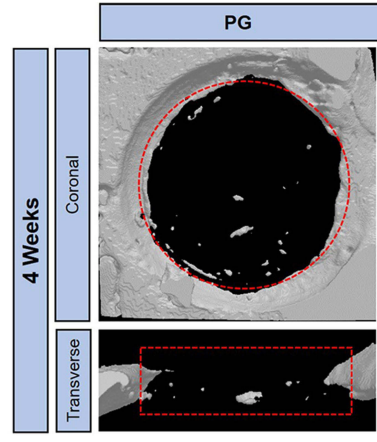

C

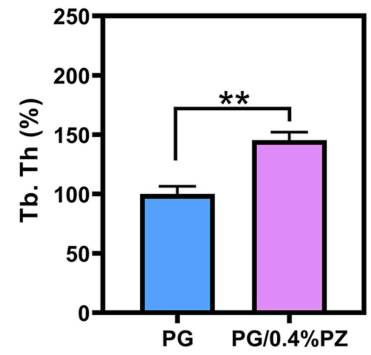

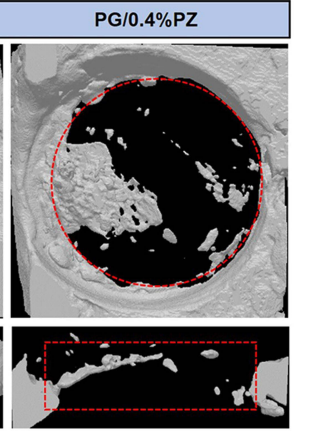

D

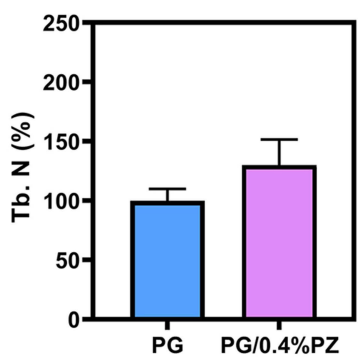

B

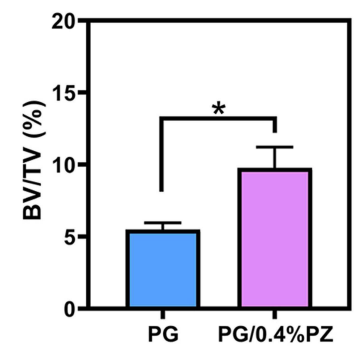

$\mathbf{E}$

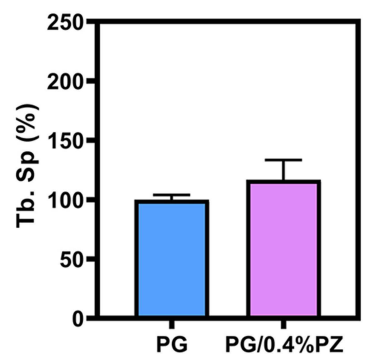

Figure 8 (A) Typical micro-CT images of the cranial bone defect area marked with dotted circle/rectangle after 4 weeks; quantitative statistics of bone volume/total volume (BV/TV, (B)), trabecular thickness (Tb.Th, $(\mathbf{C}))$, trabecular number (Tb.N, (D)), and trabecular separation $($ Tb.Sp, $(\mathbf{E}))$. Error bars represent mean \pm SD, $* p<0.05, * * p<$ 0.01 .

range (optimal concentration $0.4 \%$ ) could play the following roles: at the cellular level, it protected osteoblasts from oxidative stress injury and restored cell proliferation and osteogenic differentiation; at the protein level, it could upregulate Nrf2, HO-1, SOD1 signaling molecules; at the animal level, it accelerated the bone formation to repair the defects 
suffering from osteoporosis complications. Therefore, the PZ-loaded GBR membranes (especially PG/0.4\%PZ) have great clinical potential for the repair of bone injury in patients with high oxidative stress.

\section{Acknowledgments}

This work was funded by the National Natural Science Foundation of China (82171004), Zhejiang Provincial Science and Technology Project for Public Welfare (LY21H180006 and LGF21H140004), Key Technological Innovation Projects of Wenzhou (ZY2019009), and Wenzhou Medical University Basic Scientific Research Operating Expenses (KYYW201905).

\section{Disclosure}

The authors have no conflicts of interest to declare.

\section{References}

1. Henslee AM, Spicer PP, Yoon DM, et al. Biodegradable composite scaffolds incorporating an intramedullary rod and delivering bone morphogenetic protein-2 for stabilization and bone regeneration in segmental long bone defects. Acta Biomater. 2011;7(10):3627-3637. doi:10.1016/j.actbio.2011.06.043

2. Omar O, Elgali I, Dahlin C, Thomsen P. Barrier membranes: more than the barrier effect? J Clin Periodontol. 2019;46 Suppl 21:103-123. doi:10.1111/jcpe. 13068

3. Elgali I, Omar O, Dahlin C, Thomsen P. Guided bone regeneration: materials and biological mechanisms revisited. Eur J Oral Sci. 2017;125(5):315-337. doi:10.1111/eos.12364

4. Santos DM. Advances in functional polymer nanofibers from spinning fabrication techniques to recent biomedical applications. ACS Appl Mater Interfaces. 2020;12(41):45673-45701. doi:10.1021/ acsami.0c12410

5. Shitole AA, Raut P, Giram P, et al. Poly (vinylpyrrolidone)-iodine engineered poly ( $\varepsilon$-caprolactone) nanofibers as potential wound dressing materials. Mater Sci Eng C Mater Biol Appl. 2020;110:110731. doi:10.1016/j.msec.2020.110731

6. Lan X. Multidrug-loaded electrospun micronanofibrous membranes Fabrication strategies, release behaviors and applications in regenerative medicine. J Controlled Release. 2020;330:1264-1287. doi:10. 1016/j.jconrel.2020.11.036

7. Ajmal G, Bonde GV, Mittal P, et al. Biomimetic PCL-gelatin based nanofibers loaded with ciprofloxacin hydrochloride and quercetin: a potential antibacterial and anti-oxidant dressing material for accelerated healing of a full thickness wound. Int $J$ Pharm. 2019;567:118480. doi:10.1016/j.ijpharm.2019.118480

8. Chen W, Wang C, Gao Y, et al. Incorporating chitin derived glucosamine sulfate into nanofibers via coaxial electrospinning for cartilage regeneration. Carbohydr Polym. 2020;229:115544. doi:10.1016/ j.carbpol.2019.115544

9. Luo J, Zhu J, Wang L, Kang J, Wang X, Xiong J. Co-electrospun nano-/microfibrous composite scaffolds with structural and chemical gradients for bone tissue engineering. Mater Sci Eng C Mater Biol Appl. 2021;119:111622. doi:10.1016/j.msec.2020.111622

10. Ghitescu RE, Popa AM, Popa VI, Rossi RM, Fortunato G. Encapsulation of polyphenols into pHEMA e-spun fibers and determination of their antioxidant activities. Int J Pharm. 2015;494 (1):278-287. doi:10.1016/j.ijpharm.2015.08.020
11. Kim K, Luu YK, Chang C, et al. Incorporation and controlled release of a hydrophilic antibiotic using poly(lactide-co-glycolide)-based electrospun nanofibrous scaffolds. J Control Release. 2004;98 (1):47-56. doi:10.1016/j.jconrel.2004.04.009

12. Song JH, Kim HE, Kim HW. Production of electrospun gelatin nanofiber by water-based co-solvent approach. J Mater Sci Mater Med. 2008;19(1):95-102. doi:10.1007/s10856-007-3169-4

13. Izquierdo R, Garcia-Giralt N, Rodriguez MT, et al. Biodegradable PCL scaffolds with an interconnected spherical pore network for tissue engineering. $J$ Biomed Mater Res A. 2008;85(1):25-35. doi:10.1002/jbm.a.31396

14. Chong EJ, Phan TT, Lim IJ, et al. Evaluation of electrospun PCL/ gelatin nanofibrous scaffold for wound healing and layered dermal reconstitution. Acta Biomater. 2007;3(3):321-330. doi:10.1016/j. actbio.2007.01.002

15. You P, Liu Y, Wang X, Li B, Wu W, Tang L. Acellular pericardium: a naturally hierarchical, osteoconductive, and osteoinductive biomaterial for guided bone regeneration. J Biomed Mater Res A. 2021;109 (2):132-145. doi:10.1002/jbm.a.37011

16. Calciolari E, Mardas N, Dereka X, Anagnostopoulos AK, Tsangaris GT, Donos N. The effect of experimental osteoporosis on bone regeneration: part 2, proteomics results. Clin Oral Implants Res. 2017;28(9):e135-e145. doi:10.1111/clr.12950

17. Calciolari E, Mardas N, Dereka X, Kostomitsopoulos N, Petrie A, Donos N. The effect of experimental osteoporosis on bone regeneration: part 1, histology findings. Clin Oral Implants Res. 2017;28(9): e101-e110. doi:10.1111/clr.12936

18. Segredo-Morales E, García-García P, Reyes R, Pérez-Herrero E, Delgado A, Évora C. Bone regeneration in osteoporosis by delivery BMP-2 and PRGF from tetronic-alginate composite thermogel. Int J Pharm. 2018;543(1-2):160-168. doi:10.1016/j.ijpharm.2018. 03.034

19. Segredo-Morales E, Reyes R, Arnau MR, Delgado A, Évora C. In situ gel-forming system for dual BMP-2 and 17 $\beta$-estradiol controlled release for bone regeneration in osteoporotic rats. Drug Deliv Transl Res. 2018;8(5):1103-1113. doi:10.1007/s13346-018-0574-9

20. Chen K, Qiu P, Yuan Y, et al. Pseurotin A inhibits osteoclastogenesis and prevents ovariectomized-induced bone loss by suppressing reactive oxygen species. Theranostics. 2019;9(6):1634-1650. doi:10.71 50/thno. 30206

21. Arioka M, Zhang X, Li Z, et al. Osteoporotic changes in the periodontium impair alveolar bone healing. J Dent Res. 2019;98 (4):450-458. doi:10.1177/0022034518818456

22. Domazetovic V, Marcucci G, Iantomasi T, Brandi ML, Vincenzini MT. Oxidative stress in bone remodeling: role of antioxidants. Clin Cases Miner Bone Metab. 2017;14(2):209-216. doi:10.11138/ccmbm/2017.14.1.209

23. Zhao F, Guo L, Wang X, Zhang Y. Correlation of oxidative stress-related biomarkers with postmenopausal osteoporosis: a systematic review and meta-analysis. Arch Osteoporos. 2021;16 (1):4. doi:10.1007/s11657-020-00854-w

24. Valko M, Izakovic M, Mazur M, Rhodes CJ, Telser J. Role of oxygen radicals in DNA damage and cancer incidence. Mol Cell Biochem. 2004;266(1-2):37-56. doi:10.1023/b:mcbi.0000049134.69131.89

25. Huang Y, Du Z, Wei P, et al. Biodegradable microspheres made of conductive polyorganophosphazene showing antioxidant capacity for improved bone regeneration. Chem Eng J. 2020:397. doi:10.1016/j. cej.2020.125352

26. Pinna A, Torki Baghbaderani M, Vigil Hernandez V, et al. Nanoceria provides antioxidant and osteogenic properties to mesoporous silica nanoparticles for osteoporosis treatment. Acta Biomater. 2021;122:365-376. doi:10.1016/j.actbio.2020.12.029

27. Yoshikawa T, Naito Y, Tanigawa T, Yoneta T, Kondo M. The antioxidant properties of a novel zinc-carnosine chelate compound, N-(3-aminopropionyl)-L-histidinato zinc. Biochim Biophys Acta. 1991;1115(1):15-22. doi:10.1016/0304-4165(91)90005-2 
28. Ueki S, Seiki M, Yoneta T, et al. Effect of Z-103 on compound 48/ 80 -induced gastric lesions in rats. Scand J Gastroenterol Suppl. 1989;162:202-205. doi:10.3109/00365528909091161

29. Maywald M, Wessels I, Rink L. Zinc Signals and Immunity. Int J Mol Sci. 2017;18(10):2222. doi:10.3390/ijms18102222

30. Pormohammad A, Monych NK, Turner RJ. Zinc and SARS-CoV-2: a molecular modeling study of $\mathrm{Zn}$ interactions with RNA-dependent RNA-polymerase and 3C-like proteinase enzymes. Int J Mol Med. 2021;47(1):326-334. doi:10.3892/ijmm.2020.4790

31. Beyersmann D, Haase H. Functions of zinc in signaling, proliferation and differentiation of mammalian cells. Biometals. 2001;14(34):331-341. doi:10.1023/a:1012905406548

32. Marreiro DD, Cruz KJ, Morais JB, Beserra JB, Severo JS, de Oliveira AR. Zinc and Oxidative Stress: current Mechanisms. Antioxidants. 2017;6(2). doi:10.3390/antiox6020024

33. Su Y. Zinc-Based Biomaterials for Regeneration and Therapy. Trends Biotechnol. 2019;37(4):428-441. doi:10.1016/j.tibtech.2018.10.009

34. Boldyrev AA, Aldini G, Derave W. Physiology and pathophysiology of carnosine. Physiol Rev. 2013;93(4):1803-1845. doi:10.1152/ physrev.00039.2012

35. Smith E. The buffering of muscle in rigor; protein, phosphate and carnosine. J Physiol. 1938;92(3):336-343. doi:10.1113/jphysiol.1938. sp003605

36. Boldyrev A. Carnosine as a modulator of endogenous $\mathrm{Zn}(2+)$ effects. Trends Pharmacol Sci. 2001;22(3):112-113. doi:10.1016/s01656147(00)01648-5

37. Hiraishi H, Sasai T, Oinuma T, Shimada T, Sugaya H, Terano A. Polaprezinc protects gastric mucosal cells from noxious agents through antioxidant properties in vitro. Aliment Pharmacol Ther. 1999;13(2):261-269. doi:10.1046/j.1365-2036.1999.00458.x

38. Kitagawa J, Kobayashi R, Nagata Y, et al. Polaprezinc for prevention of oral mucositis in patients receiving chemotherapy followed by hematopoietic stem cell transplantation: a multi-institutional randomized controlled trial. Int $J$ Cancer. 2021;148(6):1462-1469. doi:10.1002/ijc. 33316

39. Sakagami M, Ikeda M, Tomita H, et al. A zinc-containing compound, Polaprezinc, is effective for patients with taste disorders: randomized, double-blind, placebo-controlled, multi-center study. Acta Otolaryngol. 2009;129(10):1115-1120. doi:10.1080/00016480802552550

40. Sakae K, Suka M, Yanagisawa H. Polaprezinc (Zinc-L-Carnosine Complex) as an Add-on Therapy for Binge Eating Disorder and Bulimia Nervosa, and the Possible Involvement of Zinc Deficiency in These Conditions A Pilot Study. J Clin Psychopharmacol. 2020;40 (6):599-606. doi:10.1097/JCP.0000000000001284

41. Sakae K, Yanagisawa H. Oral treatment of pressure ulcers with polaprezinc (zinc L-carnosine complex): 8-week open-label trial. Biol Trace Elem Res. 2014;158(3):280-288. doi:10.1007/s12011014-9943-5

42. Hewlings S, Kalman D. A Review of Zinc-L-Carnosine and Its Positive Effects on Oral Mucositis, Taste Disorders, and Gastrointestinal Disorders. Nutrients. 2020;12(3):665. doi:10.3390/ nu12030665

43. Ren K, Wang Y, Sun T, Yue W, Zhang H. Electrospun PCL/gelatin composite nanofiber structures for effective guided bone regeneration membranes. Materials Sci Eng. 2017;78:324-332. doi:10.1016/j. msec.2017.04.084

44. Pavliňáková V, Fohlerová Z, Pavliňák D, Viera Khunová VL. Potential of Chrysin-loaded PCL-gelatin nanofibers for modulation of macrophage functional polarity towards anti-inflammatory pro-regenerative phenotype. Mater Sci Eng C Mater Biol Appl. 2018;91:94-102. doi:10.1016/j.msec.2018.05.033

45. Rajzer I, Menaszek E, Kwiatkowski R, Planell JA, Castano O. Electrospun gelatin/poly( $\varepsilon$-caprolactone) fibrous scaffold modified with calcium phosphate for bone tissue engineering. Mater Sci Eng C Mater Biol Appl. 2014;44:183-190. doi:10.1016/j.msec.2014. 08.017
46. Unalan I, Endlein SJ, Slavik B, et al. Evaluation of Electrospun Poly ( $\varepsilon$-Caprolactone)/Gelatin Nanofiber Mats Containing Clove Essential Oil for Antibacterial Wound Dressing. Pharmaceutics. 2019;11 (11):570. doi:10.3390/pharmaceutics 11110570

47. Castelletto V, Cheng G, Greenland BW, Hamley IW, Harris PJ. Tuning the self-assembly of the bioactive dipeptide L-carnosine by incorporation of a bulky aromatic substituent. Langmuir. 2011;27 (6):2980-2988. doi:10.1021/la104495g

48. Binulal NS, Natarajan A, Menon D, Bhaskaran VK, Mony U, Nair SV. PCL-gelatin composite nanofibers electrospun using diluted acetic acid-ethyl acetate solvent system for stem cell-based bone tissue engineering. J Biomater Sci Polym Ed. 2014;25(4):325-340. doi:10.1080/09205063.2013.859872

49. Bolgen N, Menceloglu YZ, Acatay K, Vargel I, Piskin E. In vitro and in vivo degradation of non-woven materials made of poly(epsilon-caprolactone) nanofibers prepared by electrospinning under different conditions. J Biomater Sci Polym Ed. 2005;16(12):1537-1555. doi:10.1163/156856205774576655

50. Zandi N, Lotfi R, Tamjid E, Shokrgozar MA, Simchi A. Core-sheath gelatin based electrospun nanofibers for dual delivery release of biomolecules and therapeutics. Mater Sci Eng C Mater Biol Appl. 2020;108:110432. doi:10.1016/j.msec.2019.110432

51. Zhang J, Wang X, Liu T, Liu S, Jing X. Antitumor activity of electrospun polylactide nanofibers loaded with 5-fluorouracil and oxaliplatin against colorectal cancer. Drug Deliv. 2016;23 (3):794-800. doi:10.3109/10717544.2014.916768

52. Liu W, Walker G, Price S, Yang X, Li J, Bunt C. Electrospun membranes as a porous barrier for molecular transport: membrane characterization and release assessment. Pharmaceutics. 2021;13 (6):916. doi:10.3390/pharmaceutics 13060916

53. Sharif R, Thomas P, Zalewski P, Graham RD, Fenech M. The effect of zinc sulphate and zinc carnosine on genome stability and cytotoxicity in the WIL2-NS human lymphoblastoid cell line. Mutat Res. 2011;720(1-2):22-33. doi:10.1016/j.mrgentox.20 10.12.004

54. Ooi TC, Chan KM, Sharif R. Antioxidant, Anti-inflammatory, and Genomic Stability Enhancement Effects of Zinc 1-carnosine A Potential Cancer Chemopreventive Agent. Nutr Cancer. 2017;69 (2):201-210. doi:10.1080/01635581.2017.1265132

55. Jessica RC, Priestley KE, Casati MC, Endres BT, Geurts AM, Lombard JH. Casati, Bradley T. The NRF2 knockout rat: a new animal model to study endothelial dysfunction, oxidant stress, and microvascular rarefaction. Am J Physiol Heart Circ Physiol. 2016;310:H478-H487. doi:10.1152/ajpheart.00586.2015

56. Ooi TC, Chan KM, Sharif R. Zinc L-Carnosine Protects CCD-18co Cells from L-Buthionine Sulfoximine-Induced Oxidative Stress via the Induction of Metallothionein and Superoxide Dismutase 1 Expression. Biol Trace Elem Res. 2020;198(2):464-471. doi:10.1007/s12011-020-02108-9

57. Ooi TC, Chan KM, Sharif R. Zinc L-carnosine suppresses inflammatory responses in lipopolysaccharide-induced RAW 264.7 murine macrophages cell line via activation of $\mathrm{Nrf} 2 / \mathrm{HO}-1$ signaling pathway. Immunopharmacol Immunotoxicol. 2017;39(5):259-267. doi:10.1080/08923973.2017.1344987

58. Liu AL, Zhang ZM, Zhu BF, Liao ZH, Liu Z. Metallothionein protects bone marrow stromal cells against hydrogen peroxide-induced inhibition of osteoblastic differentiation. Cell Biol Int. 2004;28(12):905-911. doi:10.1016/j.cellbi.2004.09.004

59. Bai XC, Lu D, Bai J, et al. Oxidative stress inhibits osteoblastic differentiation of bone cells by ERK and NF-kappaB. Biochem Biophys Res Commun. 2004;314(1):197-207. doi:10.1016/j. bbrc.2003.12.073

60. Arai M, Shibata Y, Pugdee K, Abiko Y, Ogata Y. Effects of reactive oxygen species (ROS) on antioxidant system and osteoblastic differentiation in MC3T3-E1 cells. IUBMB Life. 2007;59(1):27-33. doi:10.1080/15216540601156188 
61. Hinoi E, Fujimori S, Wang L, Hojo H, Uno K, Yoneda Y. Nrf2 negatively regulates osteoblast differentiation via interfering with Runx2-dependent transcriptional activation. J Biol Chem. 2006;281 (26):18015-18024. doi:10.1074/jbc.M600603200
62. Zhao Z, Li G, Ruan H, et al. Capturing Magnesium Ions via Microfluidic Hydrogel Microspheres for Promoting Cancellous Bone Regeneration. ACS Nano. 2021;15(8):13041-13054. doi:10.1021/acsnano. $1 \mathrm{c} 02147$

\section{Publish your work in this journal}

The International Journal of Nanomedicine is an international, peerreviewed journal focusing on the application of nanotechnology in diagnostics, therapeutics, and drug delivery systems throughout the biomedical field. This journal is indexed on PubMed Central, MedLine, CAS, SciSearch ${ }^{\mathbb{B}}$, Current Contents ${ }^{\mathbb{B}} /$ Clinical Medicine, $^{2}$
Journal Citation Reports/Science Edition, EMBase, Scopus and the Elsevier Bibliographic databases. The manuscript management system is completely online and includes a very quick and fair peer-review system, which is all easy to use. Visit http://www.dovepress.com/ testimonials.php to read real quotes from published authors. 